\title{
Layers of woundedness in Inxeba: masculinities disrupted, denied
}

and defamed

$>\quad$ Peace Kiguwa

Department of Psychology, University of the Witwatersrand, Johannesburg, South Africa

peace.kiguwa@wits.ac.za (preferred pronouns: she/her)

$>\quad$ Anele Siswana

Department of Psychology, University of Johannesburg, Johannesburg, South Africa

aneles@uj.ac.za (preferred pronouns: he/him)

\section{ABSTRAC'T}

In this paper, we discuss the multi-layered representations of masculinities as they appear in the film Inxeba. Reading these multi-layered representations against a backdrop of the initiation practice of ulwaluko highlights the significance of heteronormativity in defining and engaging critical African Black masculinities in South Africa today. This is further compounded through the intersecting nuances of race and class configurations that matter for how contemporary Black masculinities are constructed. We argue that Inxeba's successes and failures of representation bring to the fore intricate debates and ethical dilemmas of representation in the arts and social sciences more generally. In addition, if Inxeba fails in its (mis)representation of ulwaluko as less than a complex, nuanced and rich cultural practice, it is arguably successful in its exploration of the deeply entrenched heteronormative socio-material and psychical space of this practice.

Keywords: Inxeba (Trengove 2017), heteronormativity, ulwaluko, representation of masculinities.

Given our engagement with issues of mis(representation) and analyses of masculinities as they appear in the film Inxeba (Trengove 2017), it is perhaps useful to engage with our own self-location and politics. One of us is a self-identified Black Xhosa gay man who has undergone the initiation practice of ulwaluko. The other is a self-identified Black lesbian woman who writes from the position of an outsider to both the cultural and gendered space of male initiation practice. 


\section{Introduction}

'Black men loving Black men is the revolutionary act of our time' (Riggs 1989).

Inxeba centres on three male characters: Xolani, Vija and Kwanda. Xolani and Vija are both amakhankatha (caregivers) assigned to different groups of young initiates during the amaXhosa male initiation practice of ulwaluko, where young boys undergo circumcision and other rites of passage as part of the process of becoming men. These two men are also in a (closeted) sexual and romantic relationship. Kwanda is a young, openly gay and impetuous initiate assigned to Xolani, and he continually provokes his caregiver and the rest of his peers and the elders on their practice and tradition. Throughout the film, we witness Xolani and Vija often engaged in conflictual interactions that address the frustrations and anxieties of struggling to live openly as Xhosa gay men. This conflict is also marked by interpersonal dynamics between the two men that pinpoint to other intersections of power and desire. Quietly observing from the side, and at times becoming an instrumental pawn in this brewing conflict, is Kwanda, whose observing audacity is progressively deemed dangerous to the two men. The film's end, in which Xolani apparently kills Kwanda, is a powerful commentary on the ramifications of the affective economies of fear and shame that are central to the reinforcement of heteronormative practice at play here.

The film has been the subject of much debate and controversy, attesting to the often affective contentious nature and practice of culture and its intersections with gender and sexuality in South Africa. The thrust of this debate and controversy has primarily centred on the representation of the ulwaluko. Critics of the film have pointed out the sacrilege of representing and making public details of the ulwaluko practice, considered sacred and not available for public observation. Indeed, the notion of male circumcision practices as sacred is an old debate that saw the protest against and eventual recall of the 2007 SABC television documentary Umthunzi Wentaba, which depicted the initiation ritual and was boycotted following protest by traditional leaders (Hawker \& Makoba 2007). The different periods of these two media releases and the resultant boycotts and protests highlight some of the troubling nuances of representation in the media as it pertains to sociocultural groups and forms of practice in society. Troubling questions arise: how do we engage a politics of representation of social groups that do not want their stories told publically?

Such a politics of representation is intricately concerned with who tells stories and what kinds of stories are told - an ethical and political dilemma of representation important within the social sciences (Macbeth 2001). However, if we are to accept 
that part of the social sciences' mandate include the responsibility to tell and make known stories that speak to understandings of what it means to be human - stories that grapple with the structural and intimate configurations of power, subjectivities, desire and pleasure - then this dilemma becomes fairly easy to resolve. Whether or not these stories "belong" to us or are part of our experiences and sociocultural identifications should not hinder their re(telling).

And yet, a further troubling dimension to this process of narration is the question of how we authentically tell the stories of/about the Other. By authentic we mean the process of telling stories about the Other's experience and practice in ways that do not denigrate and belittle that experience. How do we stimulate self-reflection about our society and place in society through artistic mediums? How do we tell stories that invite introspection that influences us to change and disrupt practices of exclusion, powerlessness and prejudice? How do we tell stories that do not reproduce stereotypical understandings of a people's identity, culture and practice? Against the background of these questions, we argue that the film Inxeba both succeeds and fails in its (mis) representations and narrative re-telling of the Other. We discuss these successes and failures, and explore the importance of engaging film and representation through a multi-layered reading that must be informed by an understanding of a situated culturalsocio-history and politics.

Part of the film's success is evident in this exploration of multiple and intersecting spaces of representing stories - stories that reveal the possibilities as well as the impediments to freeing up sexuality. The film engages and envisions the economies of practice and affect that hold heteronormative society in place - whether it is in the constant sense of surveillance and threat of being "found out", or in the affective economies of shame and fear that are part of non-normative sexual practice. In the revelation and exploration of these multiple intersecting layers of wounding and being wounded, Inxeba reveals patriarchal and heteronormative society to itself. And it is in the character of Kwanda's constant refusal to tend to society's wounding and individual woundedness through hiding and denial of self that he arises as emblematic of (South) Africa's new stories.

\section{Layers of being wounded: physical and affective dimensions of wounding and healing}

Inxeba, ultimately, is a moving narrative about Black men daring to love one another. The characters of Xolani and Vija are symbolic representations of stories that navigate 
the policing of love, desire and pleasure within a culture and society that valorises hegemonic and normative meanings of what it means to be a man. This love story's juxtaposition with the cultural story of ulwaluko is perhaps the film's most daring and critical contribution to not only unravelling the hegemony of heteronormative space but also to expose how desire's intersection with culture and race makes it both troubling and dangerous. The surveillance of male sexual desire that the film explores makes clear the social expectations for black male sexuality. In the end, the death of Kwanda, at the hands of another gay man, raises challenging questions about this surveillance and self-policing, and about the self-internalisations of shame and denial.

In exploring these multiple and intersecting layers of woundedness, we seek to engage with a critique of masculinities that incorporates social, material and affective tools. These multiple lenses, we believe, are crucial to understanding the nuances and contradictions of power and the practice of heteronormativity, and allow us to engage masculinities in terms of the multiple, contradicting and at times intersecting layers of woundedness and healing. DeBarros (2018) argues that the film's title refers to the physical cutting of the foreskin which leaves a wound. This does not only involve physical pain but also involves a psychological wound because of the complexities of the initiation process (DeBarros 2018).

To tell the story right, the correct terminology should be used. According to Douglas, Maluleke and Nakin (2014), ulwaluko has several stages and the first phase begins with ukweluswa (removal of the foreskin) using umdlanga (a double sided sharp spear) (see Lungcuzo 2013; Ntombana 2012). In this process, ingcibi (the initiator, who is seen as a socially respected man) conducts the procedure yokwelusa (the removal of the foreskin), while the ingcibi is usually surrounded by a group of men who confirm that the procedure is performed according to prescribed norms. This is a significant moment for the boy initiand (see Mhlahlo 2009; Lungcuzo 2013; Ncaca 2014). Subsequently, after ukudlangwa (the removal of the foreskin), the initiate is left with a wound (inxeba). The amaXhosa have a particular way of understanding and practicing certain rituals (Lungcuzo 2013; Ntombana 2012; Siswana 2015) and inxeba is a powerful cultural-symbolic representation of a necessary physical attribute of masculinity and what it means to be a Xhosa man (see Gqola 2007). Inxeba is also referred to as isiko - because the cut represents a core foundation of one's being and identity.

There is another aspect to be highlighted: the fact that not all cuts are the same. In different places, ukweluswa is performed differently and according to variation of amaXhosa clans. For example, abaThembu, amaMfengu, etc. perform initiation differently (Lungcuzo 2013). Furthermore, the notion of temporality needs to be addressed: isiko generally is argued to be a meaningful aspect of long-standing 
practices and rituals that have been undergone for decades and are not easy to change (Ntombana 2012). The dialogue interaction around physical pain and "curing" the wound between Kwanda as umkhwetha (new initiate) and Xolani as ikhankatha (mentor/caregiver) attests to this.

The film frames the lives of men like Xolani, Vija and Kwanda as operating in a society where non-normative sexual desire is not only taboo but governed as part of disciplinary and regulatory practice of sexuality and masculinity. Desire and sexuality are far from private domains of practice between lovers but in fact very political and contentious (see Nyanzi 2011). The notion of woundedness here takes on an affective dimension that attests to often both conscious and unconscious formations of subjectification. The psychological configurations of shame, fear, anxiety, denial and even anger are also intrinsic to these formations and influence the performative practices of masculinity. In posing questions about the psychosocial well-being and pathologies of Black men, the work of postcolonial thinkers such as Fanon and Biko remind us of the colonial psychic wounds that remain at the heart of psychological liberation. In Black skin white masks (1952), Fanon tracks pathologies of race and affect across the domains of language, sexuality, culture, dreams and behaviour to demonstrate the recalcitrance of 'pathologies of affect' in colonial trauma and wounding (Hook 2004:177). Similarly, in I write what I like (1978) Biko writes that black consciousness is only possible when it includes the psychological liberation of black men ${ }^{1}$ as a process of reclaiming black masculinities that are not violent to themselves nor to the other: 'The first step therefore is to make the black man come to himself; to pump back life into his empty shell; to infuse him with pride and dignity, to remind him of his complicity in the crime of allowing himself to be misused' (Biko 1978:29).

The nuances of woundedness beg the question: how are we wounded? The logic of sexualisation and gendered subjectification that is part of colonial history and cultural systems in Africa produce and reinforce intersecting and multiple layers of wounding that include rejection, social ostracism, ridicule and very often sexual and other forms of violence against bodies deemed to be outside the normative system of categorisation (Coetzee \& Du Toit 2018). These social wounds are further reinforced when intersected with accompanying affective wounds of shame, fear, guilt, and vulnerability (Kometsi 2004). It is also interesting that these affects are pitted against other affective economies of pleasure, desire and love that demonstrate the political, structural and psychological arrangement of sexual-racial wounds (Coetzee \& Du Toit 2018). In the film, fear and shame underpin Vija's overly and overtly macho performances of (heterosexual) masculinity. These affects function as surveillance tools, constantly reminding him that he can be found out and punished. This omnipresent disciplinary presence stands in the way of his capacity to love and express his desire for Xolani freely. In the end, 
he can only sit in deep melancholy after Kwanda finds him and Xolani in post-coitus embrace. Seeing this, Xolani takes it upon himself to eliminate the threat that Kwanda poses to him/them.

Fanon's interest in engaging with the psychic wounds of trauma and racism intersect with his interest in what it would mean for psychological liberation and healing. At its heart, Black skin white masks (1952) is an exploration of the possibilities for reclaiming the capacity for/to love in the aftermath of colonial wounding. In exploring dimensions of wounding and being wounded, we are therefore also interested in the dimensions of psychic healing. How do we tend a wound? In engaging this problematic, both Fanon and Biko engage the affective economy of love as a political project - intersecting the macro and micro complexities of subjectification. Part of this engagement, we argue, includes the recognition of the violence that exists in the denial of the Other as part of heteronormative social order. In a sense then, psychic healing symbolically entails a similar process of healing as the circumcised penis: (un)covering, exposing and laying out in the open, medicinal balms that alleviate pain and facilitate healing. The culture of secrecy and violence that normative society demands, prevents such healing and recognition of trauma. The psychic wound becomes part of the affective economies of race, sexuality and gender to reinforce the violence of heteronormative cultures and practice.

\section{Heteronormativity and the surveillance of African sexuality(ies)}

Even if Inxeba fails in its (mis)representation of ulwaluko as less than a complex, nuanced and rich cultural practice, it is arguably successful in its exploration of the deeply entrenched heteronormative socio-material and psychical space of this practice. The site of performance in this practice and process of "becoming a man" is shown to be marked by layers of disciplinary surveillance and punishment that is fundamental to heteronormative configuration. "Heteronormativity" has been used to engage those practices that include the cultural, legal, structural, interpersonal dimensions of producing subjects/subjectivities centred on binary assumptions of sex and gender (Kitzinger 2005). Such binary assumptions reinforce the view of (exclusively) two sexes and two genders; with romantic and sexual attraction pertaining to opposition between these two genders and sexes. Any configuration of gender, sex and sexual attraction that fails to meet this binary mode is considered to be unnatural and deviant. Heteronormativity as macro and micro practice thus regulates modes of subjectification (Rich 1980). Scholars (Burgess 2005; Hubbard 2008; Rich 1980) have argued that it 
is perhaps in the everyday insidiousness of heterosexual practice as the norm and as natural that heteronormativity is most successful. This normalisation of sexuality is at the heart of the interrogation of non-normative sexualities and gender expressions that fail to conform to the norm. Throughout the film Kwanda, and less explicitly Xolani, are the subjects of ridicule, hostility and jibes that question their status as men because of their perceived sexual orientation and gendered presentation.

The surveillance of Kwanda in the film begins with his own father, Khwalo. The film commences with a dialogue between Xolani and Khwalo, who hopes that Xolani (as his son's assigned caregiver) will "make a man" out of his son:

Khwalo: $\quad$... eeeh Radebe, jonga'pha ndizawuthanda uqinise isandla kule ntwana yam, yah eeh lentwana igcwele ubu bhetye-bhetye, igcwele ubu ethe-ethe lentwana (Listen here, I want you to be more firm with my son. That boy is too soft) (Trengove 2017).

Khwalo assumes that Kwanda is weak and not strong enough to withstand the physical pain that takes place in the moment of circumcision. Implicitly, he suggests that his fragility is associated with feminised traits, as it is normative in his worldview for women to be regarded as fragile and weak. He also suggests that this process is ideally meant for strong and virile boys because they are able to withstand pain and emerge as strong men, which is part of ulwaluko. In the same conversation, he blames Kwanda's mother for the way she has raised him; he suggests that the role she played in his upbringing failed to inscribe a hegemonic way of "being a boy" and contributed to his "softness". Furthermore, he highlights the possibility of hospital circumcision as an alternative for "fragile boys":

Khwalo: $\quad$ Yabona le ntwana ndinokudibana nayo isendlini nabahlobo bayo. Bamanebezivalela ezikamereni. Kodwa aziqondakali kakhuhle, ziintwana zezinhanha zelaRhawuti (Lately he's been bringing home these friends. Locking themselves in his room. Something's not right with these richboys from Johannesburg) (Trengove 2017).

There is something he is communicating at a (meta-communicative) level; he is struggling to give it a name and confront its reality. His questioning of his son's sexuality and intersecting conflation of class and urban sexualities is similar to popular constructs of "cheese boys" as representing soft (and possibly queer) masculinities (see Kiguwa \& Langa 2017; Langa 2012; Kekana 2017) that do not fit the norm for what constitutes a "real man". Langa (2012:2) reveals that boys who tend to live outside gendered norms also tend to be othered and called derogatory names. In the film, the young 
initiates discuss their processes of healing and reveal their wounds to each other in a display of one-upmanship. Kwanda is explicitly ostracised from this conversation because of his perceived sexuality. At another initiate's taunts about his sexuality and his father's class status, he responds with a taunt of his own that again aims to question the understandings of manhood that the predominant social constructs rest on. On learning that his tormentor's father is a truck driver, he sarcastically asks:

Kwanda: $\quad$ ningaba no traka balahleka iiveki zilandelelana atshintshanise iimpundu nama tyo-tyombe ase lokishini azigqibe iikuku zonke kodwa xa ibuya inyanga ikekele kufuneka abe elindwe yi plate etshisayo namanzi ashushu kuba kaloku yena yindoda kufuneka ahlonitshwe andithi yingqayi-ngayi ... (So he's one of those $\mathrm{n}^{\star \star \star \star *}$ who disappears for weeks and fucks around on your mom with a different woman in every town. And when he comes home at the end of the month he wants respect because he's the man, right?) (Trengove 2017).

Although Vija overhears and interrupts this moment, he is also moved by a curiosity and foreboding of the threat Kwanda represents to the cultural, psychic and social space fundamental to this tradition:

Vija: $\quad$ uyavuma uzongcolisa isiko wena apha (So, you are here to fuck up our ways).

Kwanda: $\quad$ Utsho njani na khankatha ... (What do you mean caregiver?) (Trengove 2017).

During a later confrontation with his caregiver, Xolani, Kwanda engages this disruption when he challenges Xolani to be honest about his own sexuality:

Kwanda: $\quad$ Ndiyakubona ukuba uyintoni kodwa wena kutheni ungakhe uyivume lonto. Undixelela ukuba mandibe yi ndoda kodwa wema awukwazi nokuzenzela lonto ngokwakho ... (I can see what you are but why are you accepting that? You want me to be a man and stand up for myself but you cannot do it yourself) (Trengove 2017).

In this scene, Kwanda directly challenges the constructs and meanings of a hegemonic masculinity that demands a denial of self. In his refusal to remain silent, Kwanda challenges a tradition of silence and complicity that individuals involved in same-sex attachments and intimate relationships experience as violence to the self. Xolani himself is something of a quiet, gentle man who now and then experiences the teasing, 
ridiculing and contempt from other men on the mountain, including his own linkwetha (young initiates), who gang up on him in a scene near the end of the film:

linkwetha: Khanki hayi ukuba asihloniphi ... (Caregiver we do not mean to disrespect you but we've been hearing stories.)

Xolani: $\quad$ Ezitheni (What about them?)

linkwetha: lentwana yasedolophini (this city boy)

Xolani: phuma egusheni, thetha lento ufuna ukuyithetha (come out straight and say what you want to say ...)

linkwetha: Wenza izinto ezimanyukunyezi ezingafunekiyo apha entabeni (You are doing nasty, unacceptable things here at the bush).

linkwetha: heeeh khanki indoda iyayenza lento uyenzayo? (What kind of man does what you do?) (Trengove 2017).

Xolani's authority as caregiver is undermined by his young initiates with the implication that respect is only confirmed and solely based on the degree of hegemonic masculinity that one is able to perform and enact. As he struggles to no avail to try and re-assert his authority in this scene, Vija (whose masculinity is uncontested and therefore worthy of commanding respect) comes to his defence and is able to restore calm.

\section{Masculinity's intersection with race and class}

Reading desire and sexuality simultaneously against a colonial history entrenched in a rigid binary gender system (see Gqola 2015; Oyèwùmí 1997) and against a cultural system that (re)produces categories of desire and pleasure as binary and heterosexual, alerts us to the underlying economies of affect central to how we understand woundedness in the film. Black gay men's sexual desire in the film is configured within other axes of vulnerability and disempowerment that include race and class. For example, in a scene where Xolani again pleads with Vija to live openly with him as his lover, a dialogue ensues that incorporates dual layers of disempowerment, shame, and fear regarding Vija's financial vulnerability and disempowerment:

Xolani: $\quad$... Uba bendithanda ngekudala ndahamba apha. Ndiyasebenza, Vija, Ndihlala ndedwa, Nditya ndedwa. Kodwa ndiyabuya, ucinga kutheni? (cwaka) Vija ujonge uXolani. Ndibuyela ukuzonceda wena ... (If I wanted 
I could have left ... Instead, I work. I eat alone. But I always come back here. Why do you think that is? [Silence]. I come back for you. To help you ...)

Vija: $\quad$ [sighs and returns cash to Xolani]

Xolani: Wenza ntoni ngoku? Ndikunile moss le mali! (What are you doing now? I have given you this money mos!)

Vija: $\quad$ Andiyifuni ... yithathe (I don't want it. Take it.)

Xolani: $\quad$ You're struggling ... I want you to have it!

Vija: $\quad$ I don't want your money

Xolani: $\quad$... Kutheni usenza lento ... (Why are you doing this! Why, why?) (Trengove 2017).

In post-apartheid South Africa, configurations of class and race matter significantly in how configurations of gender and sexuality are lived and performed. The lack of agency that Vija experiences with regards to financial status is made more complex by his closeted interactions with Xolani (who seems to have more financial capital).

Later in the film, in a silent display of power, Vija takes Xolani's young initiates on an escapade on the mountains. Xolani, recognising the unspoken performance of power, intervenes and in a show of daring decides to lead the group himself to the waterfall. They are blocked in this quest through an encounter with an unnamed white farmer constructing a fence across the path to the waterfall. What follows is an interaction between Xolani and the white farmer that asserts other layered dynamics of power related to land access and land possession - all of which bears testimony to the broader socio-political history of the country. Seeking leave to gain passageway, Xolani adopts a respectful and passive demeanour that can only be belittling to his status as ikhankatha in the presence of his initiates. It is in these moments of intersecting layers of vulnerability that Inxeba succeeds in revealing the impossibilities of manhood (Nkosi 2017) in contemporary South Africa.

In this regard, Kometsi (2004:85) observes that '[t]he active and conscious pursuit of real manhood or prescriptions of masculinity create anxiety precisely because of the shifting nature of the boundaries of masculinity'. Vija's theft of a goat from the white farmer's truck and invitation to the young initiates to join him in his daring act, further exacerbates the tension between him and Xolani. The goat is then object of a different 
re-assertion of masculinity, presented as a challenge: Vija dares the young Kwanda, a city boy, to kill the goat - the goat becomes a metaphor for a culture clash within which the battleground of masculinity is fought.

\section{Conclusion}

Finally, we return to the subject of the controversy surrounding the release of the film in South Africa, namely the public depiction of ulwaluko. Seen within the framework delineated above, while the film does not explicitly expose the practice of ulwaluko, we critique the film's representation of the cultural-symbolic significance thereof. The practice entails an educational space for acquiring cultural and indigenous knowledge systems (Ntombana 2012), and the role of ikhankatha centres on teaching and learning. As Kometsi (2004:50) observes, 'these cultural practices represent rare moments of receptivity in the construction of men and their practices, which cannot be found anywhere else'. These nuances, which function as core to the moulding and formation towards manhood, are to an extent negated by the narrative. The centring of ulwaluko in the film as predominantly about physical processes of initiation, and the healing of these physical wounds, significantly undermines the depth of this practice and tradition. In the end, in its failure to tell a story that is authentic to the practice and dignity of a people, the film fails in its promise to tell an authentically African story.

Regardless, Inxeba creates a thought-provoking exploration of social and cultural understandings of (Black) masculinity that are disrupted, denied and defamed at different moments. The three male characters discussed here confront personal, interpersonal and social struggles against a heteronormative social order that denies them a sense of belonging and self-identification as men. The film engages this by presenting multiple and intersecting layers of (dis)empowerment that attest to impossibilities of fully attaining a hegemonic ideal of masculinity. It is in these different unravellings of masculinity's intersections with race, class, geography, gender and sexuality that Inxeba most succeeds in its critique of the heteronormative. In telling a story that encompasses the complexity of gendered subjectivity, the film highlights the ubiquity of heteronormative social and cultural orders emblematic of life in contemporary South Africa.

\section{Notes}

1. Fanon and Biko have been criticised for their generic use of the gendered he or man to refer to the general population. We recognise this example of gendered languaging. 


\section{REFERENCES}

Biko, S. 1978. I write what I like. Chicago: University of Chicago Press.

Burgess, A. 2005. Queering heterosexual spaces: positive space campaigns disrupting campus heteronormativity. Canadian Woman Studies 24(2).

Coetzee, A \& du Toit, L. 2018. Facing the sexual demon of colonial power: decolonising sexual violence in South Africa. European Journal of Women's Studies 25(2):214-227.

DeBarros, L. 2018. Inxeba (The Wound): The Mamba review. [O]. http://www.mambaonline. com/2018/02/02/inxeba-wound-mamba-review Accessed 9 March 2018

Douglas, M, Maluleke, TX \& Nakin, MDV. 2014. Male circumcision: the determinant of social acceptance. Journal of Men's Health 11(4):189-195.

Fanon, F. 1952. Black skin white masks. New York: Grove Atlantic.

Gqola, PD. 2007. 'A Woman cannot marry a boy': rescue, spectacle and transitional Xhosa masculinities, in From boys to men: social constructions of masculinity in contemporary society, edited by T Shefer, K Ratele, A Strebel, N Shabalala \& R Buikema. Lansdowne: UCT Press:145-159.

Gqola, PD. 2015. Rape: a South African nightmare. Johannesburg: MF Books.

Hawker, D \& Makoba, N. 2007. SABC pulls contentious drama on circumcision. [O]. Available: https://www.iol.co.za/news/south-africa/sabc-pulls-contentiousdrama-on-circumcision-321363

Accessed 7 September 2017.

Hubbard, P. 2008. Here, there, everywhere: the ubiquitous geographies of heteronormativity. Geography Compass 2(3):640-658.

Kekana, P. 2017. The narrated social and sexual experiences of black gay university students who have sex in the closet. MA thesis, University of the Witwatersrand, Johannesburg.

Kiguwa, P \& Langa, M. 2017. 'So I decided not to invade straight black men's space': exploring heteronormative spaces on campus. South African Journal of Higher Education 31(4):53-71.

Kitzinger, C. 2005. Heteronormativity in action: reproducing the heterosexual nuclear family in after-hours medical calls. Social Problems 52(4):477-498. 
Kometsi, K. 2004. (Un)Real. AIDS Review. Centre for the study of AIDS: University of Pretoria.

Langa, M. 2012. Becoming a man: exploring multiple voices of masculinity amongst a group of young adolescent boys in Alexandra Township, South Africa. PhD thesis, University of the Witwatersrand, Johannesburg.

Lungcuzo, BW. 2013. Ulwaluko kwaXhosa. East London: National Library of South Africa.

Macbeth, D. 2001. On "reflexivity" in qualitative research: two readings, and a third. Qualitative Inquiry 7(1):35-68.

Mhlahlo, AP. 2009. 'What is manhood? The significance of traditional circumcision in the

Xhosa initiation ritual'. MA thesis, Stellenbosch University, Stellenbosch, South Africa.

Ncaca, M. 2014. Yithi uyindoda! (Say, you are a man!) An ethnographic study on the religion and masculinities in initiation schools in Cape Town townships. MA thesis, Stellenbosch University, Stellenbosch, South Africa.

Nkosi, S. 2017. The challenge of the Black Middle-Class men in negotiating the elusive masculine identities. MA thesis, University of the Witwatersrand, Johannesburg.

Ntombana, L. 2012. Should Xhosa male initiation be abolished? International Journal of Cultural Studies 14(6):631-640.

Nyanzi, S. 2011. Unpacking the [govern]mentality of African Sexualities. In African sexualities: a reader, edited by S. Tamale. Cape Town: Pambazuka: 477-502.

Oyèwùmí, O. 1997. The invention of women. Making African sense of Western gender discourses. Minneapolis: University of Minnesota Press.

Rich, A. 1980. Compulsory heterosexuality and lesbian existence. Signs: Journal of Women in Culture and Society 5(4):631-660.

Riggs, M (dir.) 1989. Tongues Untied. [Film]. Frameline.

Siswana, A. 2015. Ulwaluko kwa Xhosa: Young Xhosa men's lived experiences in the context of traditional male initiation. MA thesis, Rhodes University, Grahamstown, South Africa.

Trengove, J (dir). 2017. Inxeba. [Film]. Urucu Media. 